\title{
Characterisation of LV myocardial exercise function by 2-D strain deformation imaging in elite adolescent footballers
}

\author{
Guido E. Pieles ${ }^{1,2,3}$ - Lucy Gowing $^{1} \cdot$ Diane Ryding $^{4} \cdot$ Dave Perry $^{4} \cdot$ Steven R. McNally ${ }^{4}$ A. Graham Stuart ${ }^{2}$. \\ Craig A. Williams ${ }^{1}$
}

Received: 6 June 2019 / Accepted: 19 September 2020 / Published online: 8 October 2020

(c) The Author(s) 2020

\begin{abstract}
Purpose Few data exist on the descriptions of LV myocardial mechanics and reserve during dynamic exercise of adolescent athletes. The aim of this study was to describe the LV myocardial and cardiopulmonary changes during exercise using 2-D strain deformation imaging.

Methods Elite adolescent male football players $(n=42)$ completed simultaneous cardiopulmonary exercise testing (CPET) and exercise echocardiography measurement of LV myocardial deformation by 2-D strain imaging. LV longitudinal and circumferential 2-D strain and strain rates were analyzed at each stage during incremental exercise to a work rate of $150 \mathrm{~W}$. Additionally, exercise LV myocardial deformation and its relation to metabolic exercise parameters were evaluated at each exercise stage and in recovery using repeated measures ANOVA, linear regression and paired $t$ tests.

Results LV peak systolic baseline 2-D strain (longitudinal: $-15.4 \pm 2.5 \%$, circumferential: $-22.5 \pm 3.1 \%$ ) increased with each exercise stage, but longitudinal strain plateaued at $50 \mathrm{~W}$ (mean strain reserve $-7.8 \pm 3.0$ ) and did not significantly increase compared to subsequent exercise stages $(P>0.05)$, whilst circumferential strain (mean strain reserve $-11.6 \pm 3.3$ ) significantly increased $(P<0.05)$ throughout exercise up to $150 \mathrm{~W}$ as the dominant mechanism of exercise $\mathrm{LV}$ contractility increase. Regression analyses showed LV myocardial strain increased linearly relative to $\mathrm{HR}, \mathrm{VO}_{2}$ and $\mathrm{O}_{2}$ pulse $(P<0.05)$ for circumferential deformation, but showed attenuation for longitudinal deformation.

Conclusion This study describes LV myocardial deformation dynamics by 2-D strain and provides reference values for LV myocardial strain and strain rate during exercise in adolescent footballers. It found important differences between LV longitudinal and circumferential myocardial mechanics during exercise and introduces a methodology that can be used to quantify LV function and cardiac reserve during exercise in adolescent athletes.
\end{abstract}

Keywords Exercise stress echocardiography $\cdot$ Ventricular function $\cdot$ Myocardial reserve $\cdot$ Training $\cdot$ Adolescent athletes

\section{Abbreviations}

CPET Cardio-pulmonary exercise testing

EF Ejection faction

FFR Force-frequency relationship

Communicated by Massimo Pagani.

This article is published as part of the Special Issue on Assessment of cardiovascular function during human activities.

Guido E. Pieles

guido.pieles@bristol.ac.uk

1 Institute of Sport Exercise and Health (ISEH), University College London, London W1T 7HA, UK

2 Bristol Congenital Heart Centre, The Bristol Heart Institute, University Hospitals Bristol NHS Foundation Trust, Upper Maudlin Street, Bristol BS2 8BJ, UK
Fps Frames per second

FS Fractional shortening

GET Gas exchange threshold

IVSd Interventricular septal diastolic diameter

LV Left ventricle

LVIDd Left ventricular internal diastolic diameter

LVIDs Left ventricular internal systolic diameter
3 National Institute for Health Research (NIHR) Cardiovascular Biomedical Research Centre, Bristol Heart Institute, Upper Maudlin Street, Bristol BS2 8BJ, UK

4 Manchester United Football Club, Football Medicine and Science Department, AON Training Complex, Birch Road, Carrington, Manchester M31 4BH, UK 


$\begin{array}{ll}\text { LVPWd } & \begin{array}{l}\text { Left ventricular posterior wall diastolic } \\ \text { diameter }\end{array} \\ \mathrm{Sc} & \text { Circumferential peak systolic strain } \\ \mathrm{SCD} & \text { Sudden cardiac death } \\ \mathrm{S} 1 & \text { Longitudinal peak systolic strain } \\ \mathrm{SRc} & \text { Circumferential peak systolic strain rate } \\ \mathrm{SR} 1 & \text { Longitudinal peak systolic strain rate } \\ \mathrm{VO}_{2 \text { peak }} & \text { Peak oxygen consumption } \\ \mathrm{W} & \text { Watts } \\ \text { 2-D strain } & \text { 2-Dimensional strain }\end{array}$

\section{Introduction}

The adaptation of left ventricular (LV) morphology to athletic training in adults has been well described in several seminal publications and meta-analyses (Morganroth et al. 1975; Nishimura et al. 1980; Maron 1986; Utomi et al. 2013). But few data exist on the adaptation of the LV in the rapidly increasing population of adolescent athletes. Where available, studies in adolescent athletes have concentrated on LV morphology and cardiac functional adaptations at rest (Sharma et al. 2002; Makan et al. 2005; Di Paolo et al. 2012; Pela et al. 2016, McClean et al. 2017). Like adult athletes, adolescent athletes are also at risk of sudden cardiac death (SCD) (Malhotra et al. 2018). Importantly, 33-56\% of SCD events in young athletes occur with exertion (Roberts et al. 1980; Epstein et al. 1986; Harmon et al. 2011; Chandra et al. 2013), but the underlying pathophysiological mechanisms are poorly understood, in part, because imaging data describing LV physiology during exercise in particular in adolescents are still rare. Exercise stress echocardiography has recently, however, been shown to differentiate physiological LV functional adaptive processes from myocardial disease, where function decreases, in adult athletes (La Gerche et al. 2013; Sanz-de la Garza et al. 2017) and it has also been shown to unmask cardiac dysfunction that is not detectable at rest in the paediatric and adolescent congenital heart disease population (Roche et al. 2011, Roche et al. 2014). No studies have so far described LV myocardial response during exercise in adolescent athletes. The gold standard methodology for LV myocardial performance assessment, also during exercise, is contractility assessment by end-systolic elastance using conductance catheters, which is an invasive technique (Izawa et al. 1996; Inagaki et al. 1999). To overcome this problem and particularly important in the paediatric population, myocardial deformation imaging by 2 -D strain during exercise has recently been shown to present a more practical alternative. Furthermore, proof of principle studies including reference values for 2-D strain during exercise in non-athlete adolescents have recently become available (Boissiere et al. 2013; Pieles et al. 2015; Cifra et al. 2016).
2D strain imaging, including measurement of peak systolic strain and strain rate, is less load-dependent than other classic echocardiographic techniques of LV function, such as ejection fraction (Weidemann et al. 2002a, b). These considerations are paramount when assessing LV function during exercise with its significant pre- and after-load changes, additionally 2-D strain imaging shows angle independency, which is important to counteract significant translational heart movement during exercise. Importantly, 2-D strain at rest has been shown to differentiate adaptive from maladaptive processes in adult athletes (Kansal et al. 2011). The application of 2-D strain imaging during exercise stress echocardiography is, therefore, an appropriate methodology to enhance current practice in quantitatively assessing myocardial function and reserve in adolescent athletes.

One further challenge that remains is to integrate cardiac exercise function to the measurement of other organ systems. Cardio-pulmonary exercise testing (CPET) is the gold standard (Astrand 1971; Paridon et al. 2006) and has been used in diagnosis, risk stratification and outcome prediction in children and adults with cardiac disease (Rhodes et al. 2010; Guazzi et al. 2012). However, a major limitation of CPET is that it does not provide direct data on exerciserelated changes in myocardial function or cardiac reserve (Bassett and Howley 2000). Simultaneous measurement of cardiac performance by 2-D strain echocardiography and metabolic exercise response by CPET can, thus, overcome this limitation and a pilot study from our group has shown its suitability in healthy adolescent volunteers (Pieles et al. 2015). Therefore, the aim of this study was to utilise the integrated methodology of exercise echocardiography with CPET to describe LV myocardial exercise response in relation to exercise metabolism during strenuous exercise in adolescent elite footballers.

\section{Methods}

\section{Participants}

Forty-two healthy elite male players from an English Premier League football academy (mean age $15.4 \pm 1.7 \mathrm{y}$, stature $172.2 \pm 9.7 \mathrm{~cm}$, body mass $58.7 \pm 11.0 \mathrm{~kg}$, BMI $19.6 \pm 2.1 \mathrm{~kg} \mathrm{~m}^{2}$, lean body mass $47.2 \pm 7.5 \mathrm{~kg}$, body surface area $1.69 \pm 0.20 \mathrm{~m}^{2}$ ), volunteered to participate in this prospective cohort study and prior to participation, parent/carer and adolescents duly signed a consent form and/or an assent form, respectively. UK National Research Ethics Service (NRES) approval was obtained. Participants were screened for cardiac disease by pre-participation questionnaire physical examination, 12-lead ECG and resting echocardiography. National elite training status was defined as consisting of a minimum of $12 \mathrm{~h}$ per week training and game time and 
selection, actively participating in competition including international tournaments and possessing a contract into the clubs elite training programme (Araujo and Scharhag 2016).

\section{Cardio-pulmonary exercise testing}

An incremental CPET on a recumbent cycle ergometer (Ergosana GMBH, Bitz, Germany) positioned at a $45^{\circ}$ inclination ( $25 \mathrm{~W} \cdot 3 \mathrm{~min}^{-1}$ increments) was performed to volitional exhaustion at a pedaling frequency of $70 \pm 5 \mathrm{rpm}$. Exercise stages of $3 \mathrm{~min}$ were used to obtain a steady state and enough time to obtain echocardiographic data. Ventilation volume and expired gas composition were measured breath-by-breath using a metabolic cart (Metalyzer II, Cortex, Leipzig, Germany) with calibration, measurement and analysis of metabolic gas parameters during exercise and recovery performed as described previously (Pieles et al. 2015). Participants were requested to avoid strenuous exercise for at least $12 \mathrm{~h}$ preceding each visit and to arrive at the laboratory in a rested and hydrated state $2 \mathrm{~h}$ after a meal.

\section{Echocardiography}

Prior to exercise stress testing, participants underwent a full structural and functional resting (baseline) echocardiogram following international paediatric guidelines (Lai et al. 2006, Lopez et al. 2010). Echocardiographic measurements and analysis were performed using an Artida machine and a 2.0-4.8 MHz transducer and UltraExtendV3.2 software (Canon Medical Systems, Japan). LV diameters were measured from two-dimensional (2-D) echocardiography in the parasternal short axis view at the base of the LV. Ejection fraction (EF) was calculated using the Simpson 2-D biplane method.

\section{2-D myocardial strain analysis}

A parasternal short axis and LV focused apical 4-chamber view were captured for 2-D strain analysis. Three cardiac cycles were acquired at rates of 60-100 frames per second (Fps), analysis was performed on one manually selected cardiac cycle. The endocardial borders were manually contoured at end-systole with the range of interest adjusted to include the whole myocardium. Mean peak systolic longitudinal ( $\mathrm{Sl}$ ) and circumferential ( $\mathrm{Sc}$ ) strain were defined as the maximal deformation value of a segment during systole in the endocardial segment and is represented as a percentage (\%); mean peak systolic strain rate (SR) was defined as the maximal rate of deformation of a segment in systole over time and is expressed in 1/s (Voigt et al. 2015). Circumferential peak systolic strain was measured at the base of the LV. Mean values for circumferential and longitudinal strain were calculated for each stage only if good tracking was obtained in a minimum of four segments. Image acquisition and offline analysis were performed by an investigator experienced in paediatric echocardiography (GEP).

\section{Exercise stress echocardiography}

Exercise stress echocardiography and 2-D strain analysis were performed using the same protocol and by the same internationally accredited operator, as described by our research group previously (Pieles et al. 2015). Briefly, focused echocardiography was performed for 2-D strain analysis during free breathing exercise $60 \mathrm{~s}$ into each exercise stage at baseline (rest), 0 (unloaded pedaling), 50, 100, $150 \mathrm{~W}$ and during recovery at $2 \mathrm{~min}(\operatorname{Rec} 2)$ and $6 \mathrm{~min}(\operatorname{Rec} 6)$ after end of exercise. The gas exchange threshold (GET), representing the break point in breath-by-breath values of carbon dioxide uptake and oxygen uptake was expressed as a percentage of $\mathrm{VO}_{2 \text { peak }}$. Myocardial reserve was defined as the difference in 2-D mean peak systolic strain between baseline and each exercise stage to up to $150 \mathrm{~W}$. Strain values were not calculated at work rates higher than $150 \mathrm{~W}$ to ensure sufficient image quality and frame rate for reliable strain analysis. Only images with high frame rates of 60-100 Fps were used to ensure capture of sufficient Fps for 2-D strain analysis at higher heart rates. A minimum of 3 cardiac cycles were recorded to capture at least one cardiac cycle in expiration to obtain best image quality, which was confirmed visually and then used to perform strain analysis (Fig. 1).

\section{Statistics}

Descriptive statistics (mean and SD) of measured and derived variables were used to characterize the sample (Table 1). Prior to analyses, diagnostic plots were created to provide checks for heteroscedasticity, normality and influential observations (Figs. 2, 3). Outliers were identified as being $>1.5$ times the IQR (interquartile range) using box and whisker plots. Differences between strain and strain rate and were assessed with repeated measures ANOVA and Least Significance Difference post hoc test. Strain reserve variables were assessed using paired $t$ tests to compare between rest and individual exercise stage only. Development of myocardial deformation was tested and is described as the difference between each subsequent exercise stage (Fig. 4), as well as the differences compared to rest (Tables 2 and 3). Relationships between strain parameters and CPET variables were determined using scatterplots, Pearson's correlations and linear regression analysis (Figs. 5 and 6). All statistical analyses were performed using R Core Team (Vienna, Austria) and using SPSS Statistics Software (Version20.0. IBM Corp, USA) and GraphPad Prism (Version5.04, La Jolla, USA). A probability level of $P<0.05$ was accepted to indicate statistical significance. 


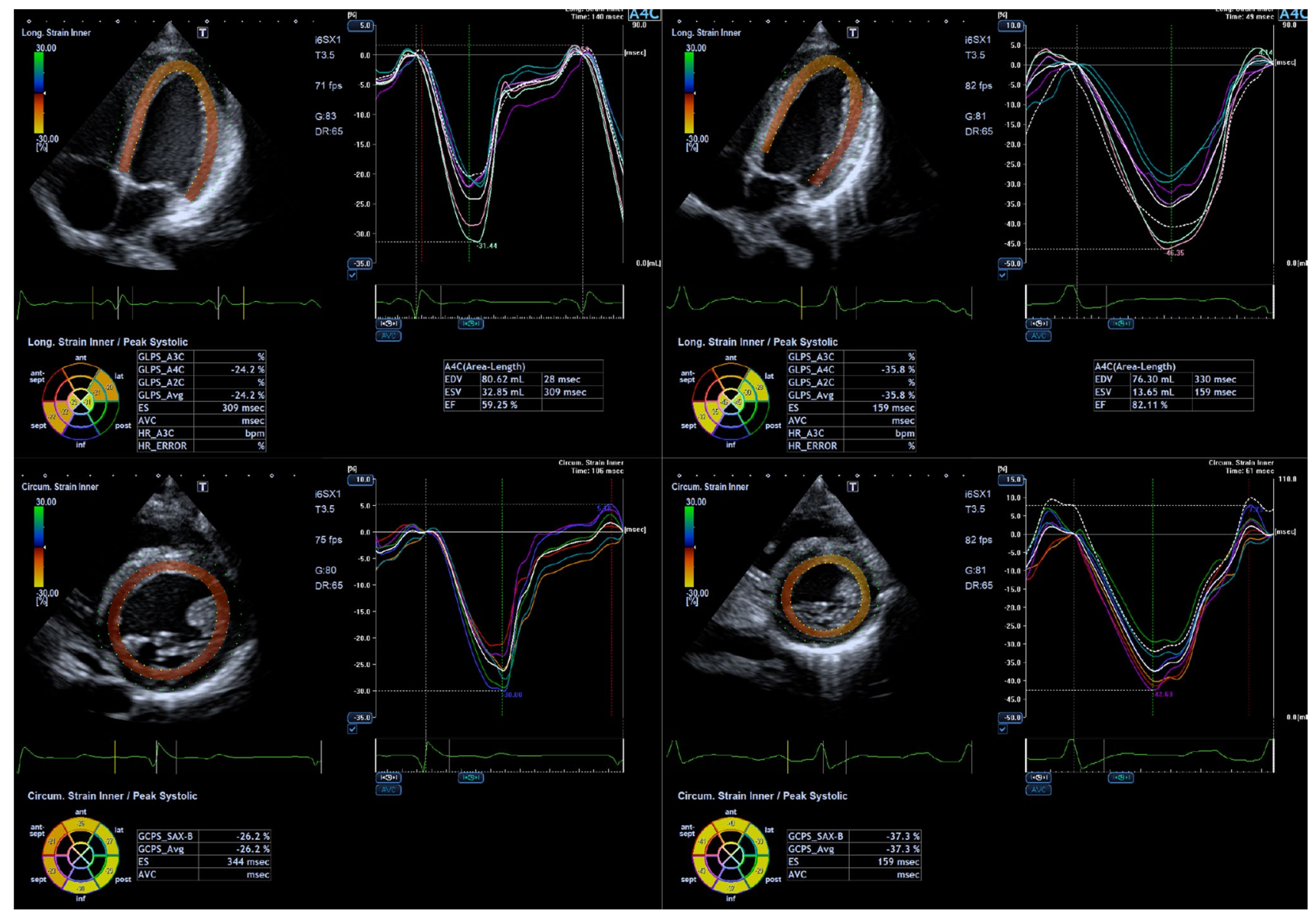

Fig. 1 Representative 2-D strain images and strain curves for LV Sl (top) and LV Sc (bottom) at baseline (left, HR=72 bpm) and during moderate exercise (right, $100 \mathrm{~W}, \mathrm{HR}=134 \mathrm{bpm}$ )

\section{Results}

All participants had a structurally and functionally normal heart. Participants had normal LV dimensions (IVSd $9.7 \pm 1.3 \mathrm{~mm}$, LVPWd $8.9 \pm 1.3 \mathrm{~mm}$, LVIDd $44.5 \pm 3.8 \mathrm{~mm}$, LVIDs $32 \pm 5.8 \mathrm{~mm}$ ) with all individual z scores within \pm 2 and normal LV systolic function with a mean FS of $33 \pm 3 \%$ and a mean EF of $64 \pm 5 \%$. Table 1 represents the mean (SD) CPET data. The exercise duration was 25:44 $\pm 5: 46$ (min:s) with a mean peak power output of $211 \pm 45 \mathrm{~W}$. Relative $\mathrm{VO}_{2 \text { peak }}$ was $49.1 \pm 6.5 \mathrm{~mL} \cdot \mathrm{kg}^{-1} \cdot \mathrm{min}^{-1}$, GET was $129 \pm 38 \mathrm{~W}$ and $69 \pm 13 \%$ of $\mathrm{VO}_{2 \text { peak }}$ or $33.3 \mathrm{~mL} \cdot \mathrm{kg}^{-1} \cdot \mathrm{min}^{-1}$. Oxygen consumption and HR as shown in Fig. 2 significantly increased linearly up to end exercise $(P<0.05)$.

\section{LV myocardial performance during exercise-2-D strain}

Analysis of 2-D LV strain was feasible up to a work rate of $100 \mathrm{~W}$ and a mean HR of $134 \pm 13 \mathrm{~b} \cdot \mathrm{min}^{-1}$ in $90 \%$ of subjects for longitudinal and $98 \%$ of subjects for circumferential strain and to $150 \mathrm{~W}$ and a mean HR of $161 \pm 16 \mathrm{~b} \cdot \mathrm{min}^{-1}$ in $60 \%$ of subjects for longitudinal and $88 \%$ for circumferential 2-D strain (Table 2). Initiation of exercise $(0 \mathrm{~W})$ resulted in a significant increase of $\mathrm{LV}$ mean peak systolic longitudinal strain (LV Sl) compared to baseline $(P=0.001)$ and this linear increase was maintained up to $50 \mathrm{~W}(P=0.001)$. A plateauing effect at the higher power outputs between 50 and $150 \mathrm{~W}$ was shown (Fig. 4), where inter-stage comparisons were not significantly different between 50 and $100 \mathrm{~W}(P=0.06)$ and 100 and $150 \mathrm{~W}(P=0.91)$ (Fig. 4.). This plateau effect for LV Sl corresponded to a $\mathrm{VO}_{2 \text { peak }}$ of between 52 and $75 \%$ (Table 1 and Figs. 3 and 4) falling into the range, where GET occurred, specifically $12 \%$ and $59 \%$ of participants were at GET at $100 \mathrm{~W}$ and $150 \mathrm{~W}$, respectively. In contrast, inter-stage comparisons from baseline and exercise stages up to $150 \mathrm{~W}$ for $\mathrm{LV}$ mean peak systolic circumferential strain $(\mathrm{Sc})$ showed a linear and significant increase (all comparisons $P=0.001$ ) (Fig. 4). LV Sl and LV Sc showed a similar profile during the recovery, during immediate recovery $(2 \mathrm{~min})$ period decreasing towards baseline level 
Table 1 Baseline, exercise, and recovery cardiopulmonary exercise testing parameters of the athlete cohort $(n=42)$

\begin{tabular}{|c|c|c|c|c|c|c|}
\hline Test stage & $\begin{array}{l}\text { Absolute } \mathrm{VO}_{2} \\
\mathrm{~L} \cdot \mathrm{min}^{-1}\end{array}$ & $\begin{array}{l}\text { Relative } \mathrm{VO}_{2} \\
\mathrm{~mL} \cdot \mathrm{kg}^{-1} \cdot \mathrm{min}^{-1}\end{array}$ & Heart rate, $\mathrm{b} \cdot \mathrm{min}^{-1}$ & $\begin{array}{l}\text { Oxygen pulse, } \\
\text { mL•beat }^{-1}\end{array}$ & $\mathrm{VO}_{2} / \mathrm{VO}_{2 \text { peak }} \%$ & $\begin{array}{l}\text { Par- } \\
\text { ticipants } \\
(n)\end{array}$ \\
\hline Baseline & - & - & $69 \pm 11$ & - & & 42 \\
\hline $0 \mathrm{~W}$ & $0.51 \pm 0.10$ & $8.86 \pm 1.84$ & $88 \pm 11$ & $5.90 \pm 1.51$ & $18.0 \pm 3.2$ & 42 \\
\hline $25 \mathrm{~W}$ & $0.67 \pm 0.12$ & $11.71 \pm 2.15$ & $97 \pm 12$ & $7.05 \pm 1.70$ & $24.0 \pm 4.7$ & 42 \\
\hline $50 \mathrm{~W}$ & $0.91 \pm 0.10$ & $15.86 \pm 2.78$ & $107 \pm 11$ & $8.55 \pm 1.51$ & $32.5 \pm 6$ & 42 \\
\hline $75 \mathrm{~W}$ & $1.18 \pm 0.12$ & $20.64 \pm 3.74$ & $120 \pm 12$ & $9.91 \pm 1.59$ & $42.4 \pm 8.6$ & 42 \\
\hline $100 \mathrm{~W}$ & $1.44 \pm 0.13$ & $25.33 \pm 4.71$ & $134 \pm 13$ & $10.84 \pm 1.50$ & $51.9 \pm 10$ & 42 \\
\hline $125 \mathrm{~W}$ & $1.75 \pm 0.18$ & $30.46 \pm 6.59$ & $148 \pm 15$ & $11.89 \pm 1.65$ & $61.4 \pm 11.5$ & 40 \\
\hline $150 \mathrm{~W}$ & $2.10 \pm 0.26$ & $36.00 \pm 7.32$ & $161 \pm 16$ & $13.30 \pm 2.26$ & $72.5 \pm 12$ & 39 \\
\hline $175 \mathrm{~W}$ & $2.34 \pm 0.23$ & $39.46 \pm 7.24$ & $168 \pm 13$ & $14.02 \pm 1.89$ & $78.5 \pm 11.0$ & 34 \\
\hline $200 \mathrm{~W}$ & $2.55 \pm 0.17$ & $40.40 \pm 6.61$ & $173 \pm 8$ & $15.02 \pm 1.39$ & $81.8 \pm 9.2$ & 23 \\
\hline $225 \mathrm{~W}$ & $2.91 \pm 0.26$ & $42.00 \pm 6.13$ & $177 \pm 10$ & $17.58 \pm 1.20$ & $85.5 \pm 10.2$ & 13 \\
\hline $250 \mathrm{~W}$ & $3.47 \pm 0.51$ & $47.37 \pm 6.73$ & $180 \pm 13$ & $20.54 \pm 0.18$ & $88.5 \pm 8.5$ & 4 \\
\hline $275 \mathrm{~W}$ & $3.90 \pm N / A$ & $50.47 \pm$ N/A & $200 \pm N / A$ & $19.48 \pm$ N/A & $83.4 \pm \mathrm{N} / \mathrm{A}$ & 1 \\
\hline Max exercise & $2.46 \pm 0.62$ & $49.11 \pm 6.54$ & $173 \pm 13$ & $13.29 \pm 3.04$ & $87.2 \pm 7.1$ & 42 \\
\hline $2 \mathrm{~min} r e c$ & $0.66 \pm 0.23$ & $11.25 \pm 2.81$ & $109 \pm 13$ & $6.09 \pm 1.86$ & $23.2 \pm 5.3$ & 42 \\
\hline $6 \mathrm{~min} \mathrm{rec}$ & $0.47 \pm 0.21$ & $7.85 \pm 2.64$ & $98 \pm 12$ & $4.86 \pm 1.89$ & $16.1 \pm 5.8$ & 42 \\
\hline
\end{tabular}

$\mathrm{CI}$ is defined as the mean \pm 2 standard deviations

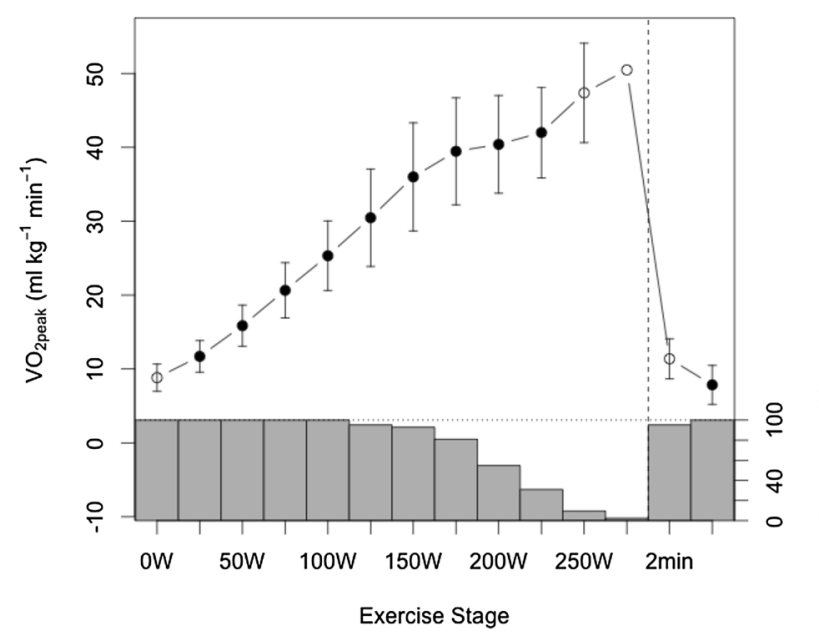

Fig. 2 Mean (SD) responses of $\mathrm{VO}_{2}$ (left) and $\mathrm{HR}$ (right) up to peak exercise and during recovery for participants. Proportion of participants that reached the respective work rates are indicated. Filled dots

to $120 \%(\mathrm{Sl})$ and $114 \%(\mathrm{Sc})$ of baseline strain, respectively, and continuing this trend to 6 min recovery. Importantly however, values did not reach baseline values at 6 min recovery $(P<0.05)$ (Table 2 and 3 ). Myocardial reserve measured by 2 -D strain was more pronounced in the circumferential plane, LV Sl reserve was $-7.8 \pm 3.0$ vs $-11.6 \pm 3.3$ for LV Sc reserve (Fig. 3). Strain rate (SR) during exercise increased significantly $(P=0.001)$ between

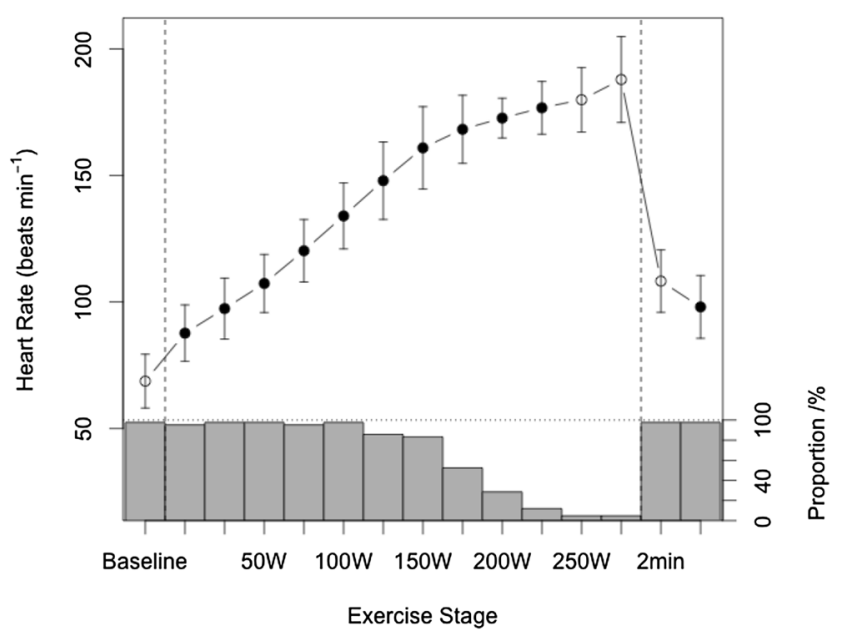

show statistical difference compared to the subsequent stage at the $P<0.05$ level. Please see also Table 1

most exercise stages for the longitudinal and circumferential myofibre direction and did not reach a plateau at higher exercise stages (Table 3 and Fig. 4). Three comparisons for longitudinal SR between $0 \mathrm{~W}$ and $6 \mathrm{~min}$ rec $(P=0.84)$ and $50 \mathrm{~W}$ and $2 \mathrm{~min}$ rec $(P=0.65)$ and circumferential SR for $0 \mathrm{~W}$ and $6 \mathrm{~min}$ rec $(P=0.75)$ were found not to be significantly different. Strain rate reserve was significantly different at all stages compared to baseline $(P<0.001)$ (Table 3). 


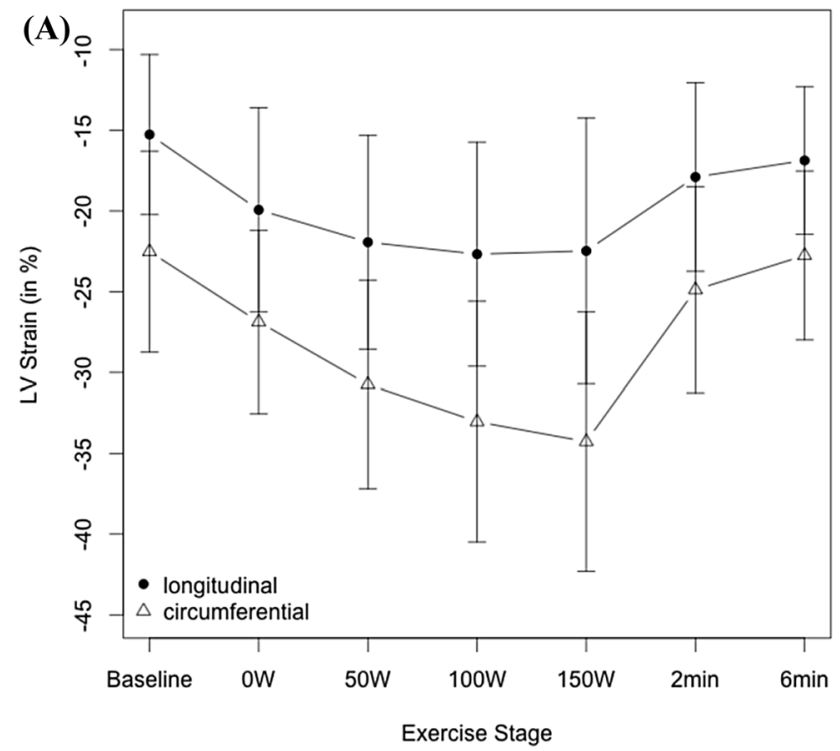

Fig. 3 a Mean LV peak systolic longitudinal strain and circumferential strain at each exercise stage (baseline to 6 min recovery); b Mean LV peak systolic longitudinal strain and circumferential strain reserve

\section{Force-Frequency relationship}

Figures 5 and 6 represent the scatterplot of the relationship between strain, strain rate and chronotropic exercise response. Both, strain and strain rate increased with HR during exercise in a moderate linear relationship, confirming a positive physiological force-frequency relationship (FFR) between HR and all investigated strain and strain rate parameters $(P<0.001)$. Sc showed a stronger correlation to heart rate than $\mathrm{Sl}\left(R^{2}=0.56\right.$ vs $\left.0.31, P<0.001\right)$ (Fig. 5). Compared to strain, strain rate showed a stronger relationship for all strain rate values (Figs. 5 and 6).

\section{Relationship between exercise myocardial performance and metabolic exercise parameters}

LV Sl, LV Sc, LV SRl and LV SRc increased linearly to absolute and relative $\mathrm{VO}_{2}$ and $\mathrm{O}_{2}$ pulse, the positive relationships are shown in the scatterplots in Figs. 5 and 6. The strength of the linear relationships was stronger for strain rate compared to strain and was also stronger for LV Sc compared to LV Sl for all variables assessed (Figs. 5 and 6).

\section{Discussion}

In this study, we describe for the first time, the LV myocardial contractile response to exercise in elite adolescent footballers by 2-D strain imaging. Using a novel approach piloted previously by our group (Pieles et al. 2015), which

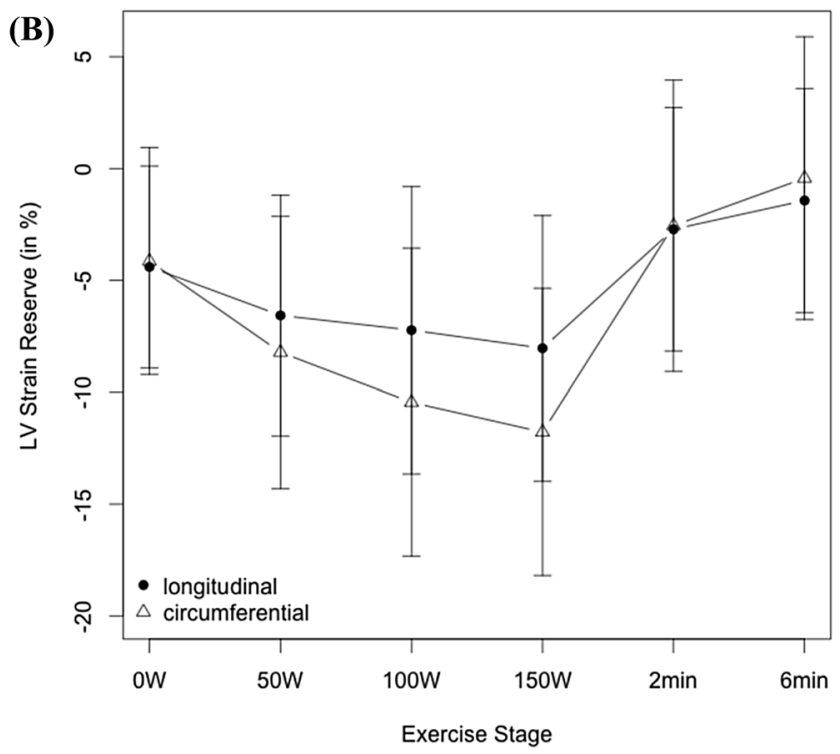

at each exercise stage (baseline to 6 min recovery) showing a plateauing effect for mean peak systolic LV longitudinal strain

combines 2-D strain imaging with simultaneous metabolic evaluation using CPET, we investigated the mechanics of LV contraction under exercise stress, as well as the relationship of exercise LV function to metabolic exercise parameters.

\section{LV myocardial performance during exercise}

Strain and strain rates at baseline were comparable to published reference data in healthy adolescents (Marcus et al. 2011). We found an incremental increase in LV Sl and LV $\mathrm{Sc}$ in response to exercise and in accordance to previous exercise strain assessment studies in adult elite athletes (La Gerche et al. 2012). The increase in LV Sc, a parameter of myocardial contractility of circumferential myocardiac fibres, was more pronounced and increased more linearly to $150 \mathrm{~W}$ whereas LV Sl, which describes contractility of longitudinal myocardial fibres, reached a plateau at moderate work rates $(50-100 \mathrm{~W})$, coinciding with GET as a possible associated mechanism. The contribution of circumferential myocardial contractility was more pronounced as shown by a higher absolute strain increase for circumferential strain over longitudinal strain $(-34.0 \pm 4 \%$ vs $-22.4 \pm 4 \%$ ), as well as a higher circumferential strain reserve $(-11.6 \pm 3.3$ vs $-7.8 \pm 3.0)$ (Figs. 3 and 4$)$. This observation points towards a differential exercise contribution of LV longitudinal and circumferential myocardial fibres with dominance of circumferential myofibre motion at higher work rates. This is in accordance with one previous adult study (Stohr et al. 2014) and also confirmed by animal studies (Kovacs et al. 2015), that showed 

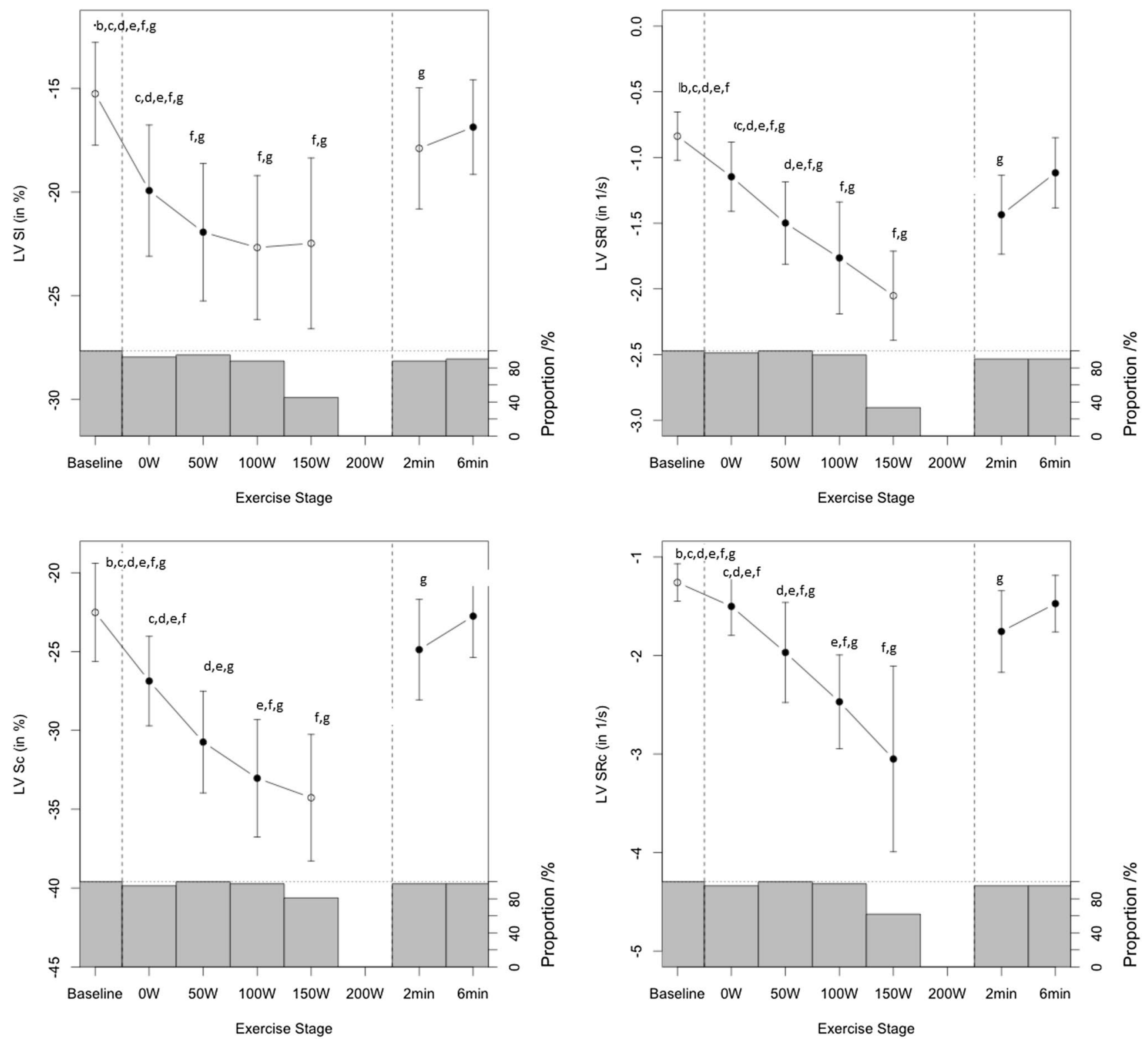

Fig. 4 Myocardial performance response during exercise as measured by mean LV peak systolic longitudinal $(\mathrm{Sl})$ and circumferential (Sc) strain and strain rate (SRl, SRc), respectively. Letters above each stage show statistical significant difference (ANOVA and post-hoc

test) in comparison with the selected exercise stage, such that letters correspond to: $\mathrm{b}=0 \mathrm{~W}, \mathrm{c}=50 \mathrm{~W}, \mathrm{~d}=100 \mathrm{~W}, \mathrm{e}=150 \mathrm{~W}, \mathrm{f}=2 \min \mathrm{rec}$ and $\mathrm{g}=6 \mathrm{~min}$ rec; (e.g. in left upper panel at baseline significant differences found compared to $0,50,100,150,2 \mathrm{~min}$ rec and $6 \mathrm{~min} \mathrm{rec}$ )

recruitment of circumferential myofibres during exercise confers a higher contractility. This observation is also in accordance with data from non-athlete adolescents in our previous study (Pieles et al. 2015). While specific loading conditions during exercise might to some degree influence our 2-D strain values (Greenberg et al. 2002), we validated this result by measuring strain rate (Table 3 and Fig. 6), which is the least load-dependent parameter (Ferferieva et al. 2012), and in accordance, absolute circumferential systolic strain rate increase was also more pronounced than longitudinal systolic strain $(-3.71 \pm 0.71$ vs $-2.05 \pm 0.34)$ as was circumferential strain rate reserve $(-2.51 \pm 0.77$ vs $-1.29 \pm 0.37)$. In contrast to strain, however, strain rate increased continuously to $150 \mathrm{~W}$ without a plateau in both fibre directions. Strain rate has previously been shown to be the most accurate noninvasive measurement of contractility during dobutamine (Greenberg et al. 2002) and exercise stress (La Gerche et al. 2012) also compared to strain. As a derivative of myocardial velocities, it is very sensitive and less influenced by pre- and afterload changes and translational tissue motion changes that even strain is susceptible to (Greenberg et al. 2002). While 
Table 2 Mean LV peak systolic longitudinal and LV peak systolic circumferential strain response during exercise

\begin{tabular}{lccccccc}
\hline Test stage & Strain value & SD & Lower CI & Upper CI & Strain reserve & $P$ value & $\begin{array}{l}\text { Partici- } \\
\text { pants } \\
(n)\end{array}$ \\
\hline LV peak systolic longitudinal strain & & & & & & \\
\hline
\end{tabular}

$P$ values compare strain parameters at each exercise stage compared to baseline. CI is defined as the mean \pm 2 standard deviations

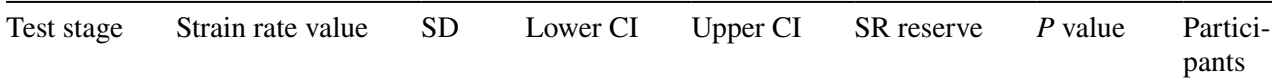

(n) systolic circumferential strain rate response during exercise

\begin{tabular}{lllllcll}
\hline \multicolumn{2}{l}{ LV peak systolic longitudinal strain rate } & & & & & \\
Baseline & -0.84 & 0.18 & -1.21 & -0.47 & $0 \pm 0$ & - & 42 \\
$0 \mathrm{~W}$ & -1.15 & 0.26 & -1.67 & -0.62 & $-0.3 \pm 0.3$ & $<0.001$ & 41 \\
$50 \mathrm{~W}$ & -1.50 & 0.31 & -2.13 & -0.87 & $-0.7 \pm 0.3$ & $<0.001$ & 42 \\
$100 \mathrm{~W}$ & -1.76 & 0.43 & -2.62 & -0.91 & $-0.9 \pm 0.5$ & $<0.001$ & 40 \\
$150 \mathrm{~W}$ & -2.05 & 0.34 & -2.73 & -1.37 & $-1.3 \pm 0.4$ & $<0.001$ & 14 \\
$2 \mathrm{~min}$ rec & -1.44 & 0.30 & -2.04 & -0.84 & $-0.6 \pm 0.3$ & $<0.001$ & 38 \\
6 min rec & -1.12 & 0.27 & -1.65 & -0.58 & $-0.3 \pm 0.3$ & $<0.001$ & 38 \\
LV peak systolic circumferential strain rate & & & & & \\
Baseline & -1.26 & 0.19 & -1.64 & -0.88 & $0 \pm 0$ & - & 42 \\
$0 \mathrm{~W}$ & -1.50 & 0.29 & -2.09 & -0.91 & $-0.2 \pm 0.3$ & $<0.001$ & 40 \\
$50 \mathrm{~W}$ & -1.97 & 0.51 & -2.98 & -0.95 & $-0.7 \pm 0.6$ & $<0.001$ & 42 \\
$100 \mathrm{~W}$ & -2.47 & 0.48 & -3.42 & -1.52 & $-1.2 \pm 0.5$ & $<0.001$ & 41 \\
$150 \mathrm{~W}$ & -3.05 & 0.94 & -4.93 & -1.17 & $-1.8 \pm 1$ & $<0.001$ & 26 \\
$2 \mathrm{~min}$ & -1.76 & 0.41 & -2.58 & -0.93 & $-0.5 \pm 0.4$ & $<0.001$ & 40 \\
$6 \mathrm{~min}$ & -1.47 & 0.29 & -2.05 & -0.90 & $-0.2 \pm 0.3$ & $<0.001$ & 40 \\
\hline
\end{tabular}

$P$ values compare strain parameters at each exercise stage compared to baseline. CI is defined as the mean \pm 2 standard deviations intrinsic myofiber contractile force still increases at higher exercise stages leading to continuous strain rate increase, this phenomenon would not have been captured as well by strain. The plateauing effect of strain values in our study, can be hypothesized to be a result of the susceptibility of strain to stroke volume changes (Weidemann et al. 2002a, b) which has been shown to not alter significantly at near maximal exercise (Higginbotham et al. 1986). Our previous data in healthy non-athlete adolescents of similar age using the same methodology (Pieles et al. 2015) showed similar development for strain and strain rate. 

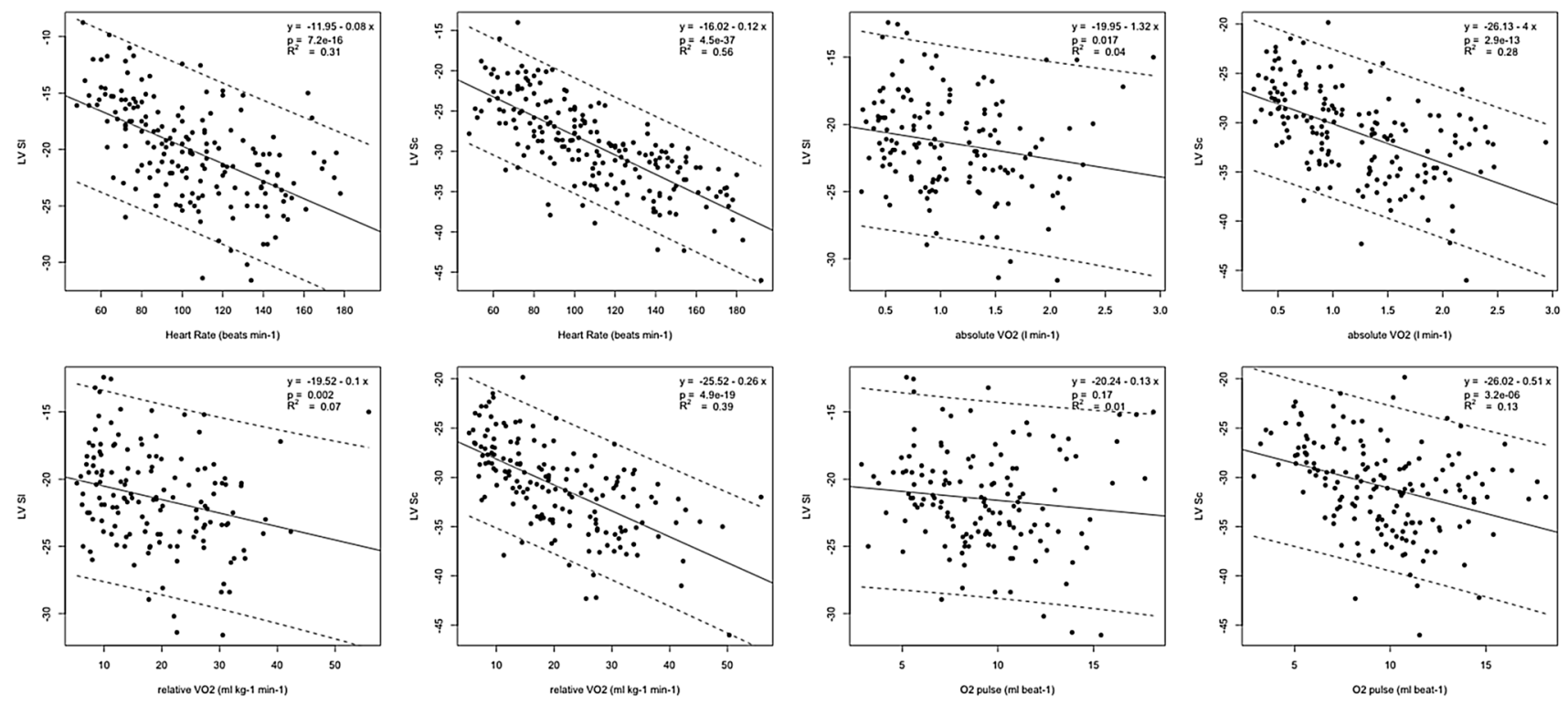

Fig. 5 Scatterplots representing the increase of LV myocardial performance as measured by mean LV peak systolic longitudinal (Sl) and circumferential $(\mathrm{Sc})$ strain in relation to HR and metabolic exercise parameters
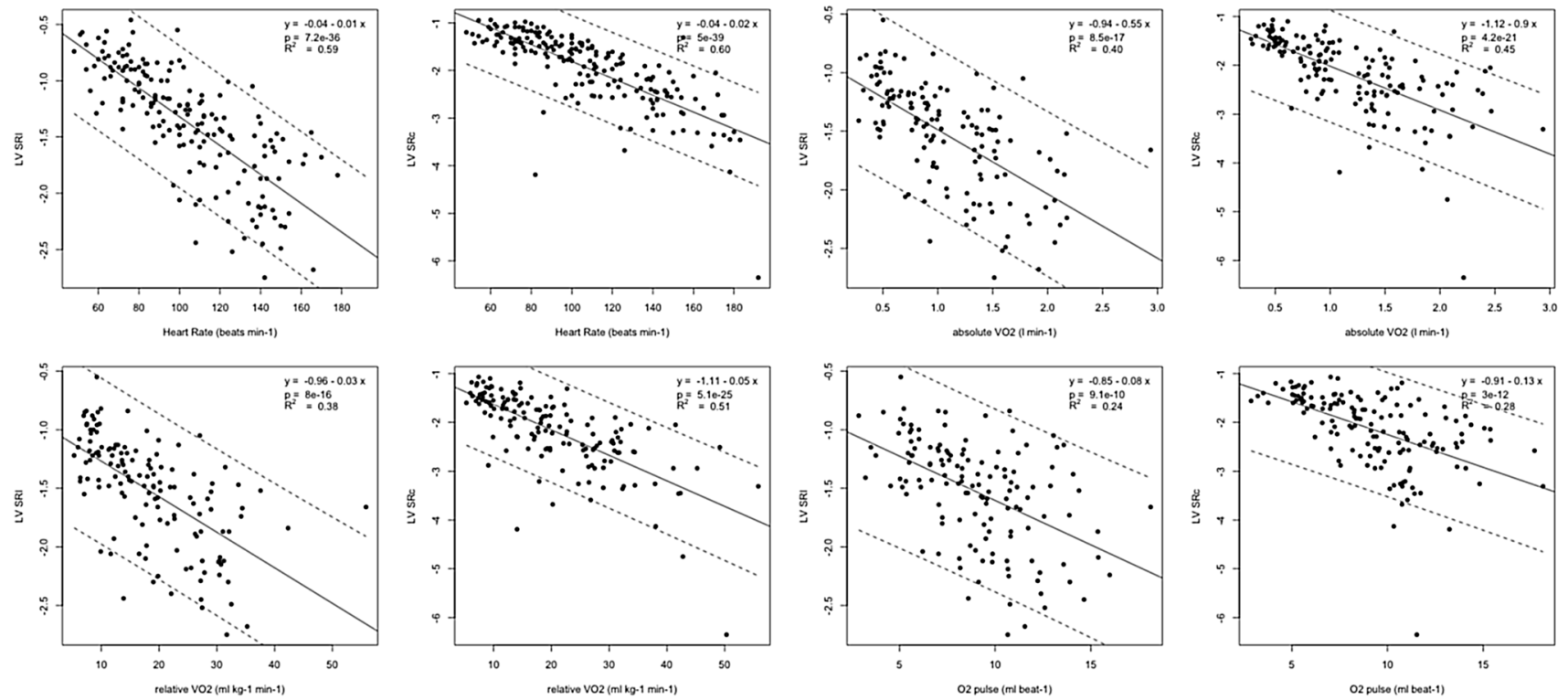

Fig. 6 Scatterplots representing the increase of LV myocardial performance as measured by mean LV peak systolic longitudinal (SRl) and circumferential (SRc) strain rate in relation to HR and metabolic exercise parameters

\section{Force-Frequency relationship}

Both, strain and strain rate followed the physiological force-frequency relationship (FFR), a fundamental relationship of healthy myocardium demonstrated in the paediatric population (Roche et al. 2011), by an incremental increase in contractility as measured by strain and strain rate in relation to HR. An abnormal FFR during exercise has recently been shown in children with heart disease (Roche et al. 2014), and hence the data on FFR development during exercise presented here could become a tool to detect early LV dysfunction in adolescent athletes. For athletes in particular, the detailed description of LV myocardial performance during exercise is of importance, as reduced 2-D strain and exercise-induced LV dysfunction are early signs in adolescent and adult subclinical hypertrophic cardiomyopathy (Sakata et al. 2008; Forsey et al. 2014), which is a major cause of sudden cardiac death in the athlete population (Malhotra 
et al. 2018). Hence, the use of 2-D strain during exercise stress echocardiography has the potential to further increase the utility of 2-D strain in the early detection of myocardial disease, in particular in athletes where myocardial disease is often concealed and remains a diagnostic challenge (Sheikh et al. 2015).

\section{LV myocardial performance in recovery}

2-D strain values at recovery showed a tendency to return to baseline values, but showed significant differences between baseline and recovery (Fig. 4 and Table 2). Equally, strain rate, as the best measure of contractility, did not return to baseline at 2 and 6 min recovery (Table 3 ), both strain and strain rate recovery mechanics indicating a higher myocardial performance demand in the recovery phase. This will also have been influenced by the higher HR via the described FFR compared to pre-exercise baseline values (Table 1). We previously described albeit statistically non-significant, a reduction of 2-D strain during recovery in a non-athlete adolescent cohort as a reflection of altered myocardial recovery function after maximal exercise (Pieles et al. 2015), but this was not observed in the athlete cohort, which might present a specific athletic myocardial adaptation, but would require a direct comparison study, that was beyond the scope of this paper.

\section{Myocardial performance and metabolic exercise parameters}

Study participants showed higher fitness levels with a superior $\mathrm{VO}_{2 \text { peak }}$ compared to previous published data in age matched non-athlete adolescents using the same exercise test methodology (Pieles et al. 2015). Ventricular mechanics are highly dependent not only on HR as discussed above, but also on exercise intensity, work rate and metabolic state (Armstrong et al. 2016). We have, therefore, also investigated the relationships between longitudinal and circumferential myocardial performance by strain and strain rate and absolute and relative $\mathrm{VO}_{2}$ and $\mathrm{O}_{2}$ pulse. Scatterplots confirmed a linear relationship (Figs. 5 and 6) for absolute and relative $\mathrm{VO}_{2}$ and $\mathrm{O}_{2}$ pulse. Importantly, as $R^{2}$ values (Figs. 5 and 6) show, there exists a stronger relationship of absolute and relative $\mathrm{VO}_{2}$ and $\mathrm{O}_{2}$ pulse with $\mathrm{Sc}$ compared to $\mathrm{Sl}$ also indicating a dominance of circumferential fibre shortening during exercise as discussed above. The relationship between strain and $\mathrm{O}_{2}$ pulse found supports the clinical use of peak $\mathrm{O}_{2}$ pulse as a surrogate parameter for cardiac function during clinical CPET testing, and vice versa, validating 2-D strain during exercise as an alternative tool to more accurately and directly measure LV myocardial function during clinical exercise testing. Here, Sc might be the superior parameter over Sl to be used during exercise stress echocardiography judging by its closer relationship to absolute and relative $\mathrm{VO}_{2}$ and $\mathrm{O}_{2}$ pulse. Further work is needed to determine if this relationship is different in the setting of myocardial disease.

\section{Limitations}

There are a number of technical challenges when assessing simultaneous echocardiography and CPET that need to be acknowledged. First is the requirement for a semisupine position to acquire satisfactory images resulting in a position-specific CPET response (Warburton et al. 2002), which was shown to be feasible and valid in children (May et al. 2013). Second, as a result of insufficient HR vs frame rate ratio, 2-D strain measurements were not performed at the maximal end-exercise stage of the test. Tissue Doppler imaging with higher acquisition frame rates could theoretically overcome this, however, this technique is angledependent and paediatric exercise studies (Cifra et al. 2016) have not yielded data at maximal exercise intensities. Good intra- and inter-observer reliability of 2-D strain measurements, paramount during exercise echocardiography (Picano et al. 1991), using the same hard- and software, protocol and the same echocardiographer were established in our previous pilot study (Pieles et al. 2015). The intra- and interobserver average variance for baseline, exercise, and recovery strain values there ranged from 0.6 to $8 \%$ with and intraclass correlation coefficient (ICC) between $r=0.78$ and 0.98 for $\mathrm{LV}$ $\mathrm{Sl}$; from 0.9 to $9.1 \%$ with ICC between $r=0.87$ and 0.98 for LV Sc. Our study cohort was extremely homogenous and a more heterogeneous sample might have provided more subtle inter-subject associations. While this is, to our knowledge to date, the largest cohort study using 2-D strain exercise echocardiography in adolescent athletes, further larger studies will need to be conducted to create large-scale normative data.

\section{Conclusion}

This study characterized the LV myocardial mechanics during exercise in elite adolescent athletes using 2-D strain imaging. It describes the normal response of myocardial function during exercise and recovery and showed, that there is a specific response of longitudinal and circumferential myocardial performance to exercise stress, knowledge that in the future might help differentiate between adaptive and maladaptive myocardial function in paediatric athletes and those with myocardial disease. Additionally, it provides the first initial reference data for 2-D strain and strain rate values of the LV during exercise in the healthy adolescent elite athlete population. 
Acknowledgements This study was supported by the National Institute for Health Research (NIHR) Biomedical Research Centre at the University Hospitals Bristol NHS Foundation Trust and the University of Bristol. The views expressed in this publication are those of the author(s) and not necessarily those of the NHS, the National Institute for Health Research or the Department of Health. At the time of the study, GEP held a NIHR Academic Clinical Lectureship. We would like to thank the athletes and staff at Manchester United Football Club Youth Academy for their commitment to this research project. This study is part of a research partnership between Canon Medical Systems UK, Manchester United Football Club and the Universities of Bristol. The research partnership between Canon Medical Systems and the University of Bristol is a contractual research partnership that determines the independence of the research from either parties' interests.

Author contributions GEP, CAW and AGS conceived and designed the research, GEP and CAW conducted experiments, analysed data, wrote and reviewed the manuscript. All authors edited, read and approved the manuscript.

\section{Compliance with ethical standards}

Conflict of interest The authors declare that they have no conflict of interest.

Open Access This article is licensed under a Creative Commons Attribution 4.0 International License, which permits use, sharing, adaptation, distribution and reproduction in any medium or format, as long as you give appropriate credit to the original author(s) and the source, provide a link to the Creative Commons licence, and indicate if changes were made. The images or other third party material in this article are included in the article's Creative Commons licence, unless indicated otherwise in a credit line to the material. If material is not included in the article's Creative Commons licence and your intended use is not permitted by statutory regulation or exceeds the permitted use, you will need to obtain permission directly from the copyright holder. To view a copy of this licence, visit http://creativecommons.org/licenses/by/4.0/.

\section{References}

Araujo CG, Scharhag J (2016) Athlete: a working definition for medical and health sciences research. Scand J Med Sci Sports 26(1):4-7

Armstrong C, Samuel J, Yarlett A, Cooper SM, Stembridge M, Stohr EJ (2016) The effects of exercise intensity vs. metabolic state on the variability and magnitude of left ventricular twist mechanics during exercise. PLoS ONE 11(4):e0154065

Astrand PO (1971) Methods of ergometry in children. Definitions, testing procedures, accuracy and reproduceability. Acta Paediatr Scand Suppl 217:9-12

Bassett DR Jr, Howley ET (2000) Limiting factors for maximum oxygen uptake and determinants of endurance performance. Med Sci Sports Exerc 32(1):70-84

Boissiere J, Maufrais C, Baquet G, Schuster I, Dauzat M, Doucende G, Obert P, Berthoin S, Nottin S (2013) Specific left ventricular twist-untwist mechanics during exercise in children. J Am Soc Echocardiogr 26(11):1298-1305

Chandra N, Bastiaenen R, Papadakis M, Sharma S (2013) Sudden cardiac death in young athletes: practical challenges and diagnostic dilemmas. J Am Coll Cardiol 61(10):1027-1040

Cifra B, Mertens L, Mirkhani M, Slorach C, Hui W, Manlhiot C, Friedberg MK, Dragulescu A (2016) Systolic and diastolic myocardial response to exercise in a healthy pediatric cohort. J Am Soc Echocardiogr 29(7):648-654

Di Paolo FM, Schmied C, Zerguini YA, Junge A, Quattrini F, Culasso F, Dvorak J, Pelliccia A (2012) The athlete's heart in adolescent Africans: an electrocardiographic and echocardiographic study. J Am Coll Cardiol 59(11):1029-1036

Ferferieva V, Van den Bergh A, Claus P, Jasaityte R, Veulemans P, Pellens M, La Gerche A, Rademakers F, Herijgers P, D'Hooge J (2012) The relative value of strain and strain rate for defining intrinsic myocardial function. Am J Physiol Heart Circ Physiol 302(1):H188-195

Forsey J, Benson L, Rozenblyum E, Friedberg MK, Mertens L (2014) Early changes in apical rotation in genotype positive children with hypertrophic cardiomyopathy mutations without hypertrophic changes on two-dimensional imaging. J Am Soc Echocardiogr 27(2):215-221

Greenberg NL, Firstenberg MS, Castro PL, Main M, Travaglini A, Odabashian JA, Drinko JK, Rodriguez LL, Thomas JD, Garcia MJ (2002) Doppler-derived myocardial systolic strain rate is a strong index of left ventricular contractility. Circulation 105(1):99-105

Guazzi M, Adams V, Conraads V, Halle M, Mezzani A, Vanhees L, Arena R, Fletcher GF, Forman DE, Kitzman DW, Lavie CJ, Myers J, Eacpr, and Aha (2012) EACPR/AHA Joint Scientific Statement. Clinical recommendations for cardiopulmonary exercise testing data assessment in specific patient populations. Eur Heart J 33(23):2917-2927

Harmon KG, Asif IM, Klossner D, Drezner JA (2011) Incidence of sudden cardiac death in National Collegiate Athletic Association athletes. Circulation 123(15):1594-1600

Higginbotham MB, Morris KG, Williams RS, McHale PA, Coleman RE, Cobb FR (1986) Regulation of stroke volume during submaximal and maximal upright exercise in normal man. Circ Res 58(2):281-291

Inagaki M, Yokota M, Izawa H, Ishiki R, Nagata K, Iwase M, Yamada Y, Koide M, Sobue T (1999) Impaired force-frequency relations in patients with hypertensive left ventricular hypertrophy. A possible physiological marker of the transition from physiological to pathological hypertrophy. Circulation 99(14):1822-1830

Izawa H, Yokota M, Nagata K, Iwase M, Sobue T (1996) Impaired response of left ventricular relaxation to exercise-induced adrenergic stimulation in patients with hypertrophic cardiomyopathy. J Am Coll Cardiol 28(7):1738-1745

Kansal MM, Lester SJ, Surapaneni P, Sengupta PP, Appleton CP, Ommen SR, Ressler SW, Hurst RT (2011) Usefulness of twodimensional and speckle tracking echocardiography in "Gray Zone" left ventricular hypertrophy to differentiate professional football player's heart from hypertrophic cardiomyopathy. Am J Cardiol 108(9):1322-1326

Kovacs A, Olah A, Lux A, Matyas C, Nemeth BT, Kellermayer D, Ruppert M, Torok M, Szabo L, Meltzer A, Assabiny A, Birtalan E, Merkely B, Radovits T (2015) Strain and strain rate by speckle tracking echocardiography correlate with pressure-volume loop derived contractility indices in a rat model of athlete's heart. Am J Physiol Heart Circ Physiol 00828:02014

La Gerche A, Burns AT, D'Hooge J, Macisaac AI, Heidbuchel H, Prior DL (2012) Exercise strain rate imaging demonstrates normal right ventricular contractile reserve and clarifies ambiguous resting measures in endurance athletes. J Am Soc Echocardiogr 25(3):253-262

La Gerche A, Baggish AL, Knuuti J, Prior DL, Sharma S, Heidbuchel H, Thompson PD (2013) Cardiac imaging and stress testing asymptomatic athletes to identify those at risk of sudden cardiac death. JACC Cardiovasc Imaging 6(9):993-1007

Lai WW, Geva T, Shirali GS, Frommelt PC, Humes RA, Brook MM, Pignatelli RH, Rychik J, E. Task Force of the Pediatric Council of 
the American Society of, and E. Pediatric Council of the American Society (2006) Guidelines and standards for performance of a pediatric echocardiogram: a report from the Task Force of the Pediatric Council of the American Society of Echocardiography. J Am Soc Echocardiogr 19(12):1413-1430

Lopez L, Colan SD, Frommelt PC, Ensing GJ, Kendall K, Younoszai AK, Lai WW, Geva T (2010) Recommendations for quantification methods during the performance of a pediatric echocardiogram: a report from the Pediatric Measurements Writing Group of the American Society of Echocardiography Pediatric and Congenital Heart Disease Council. J Am Soc Echocardiogr 23(5):465-495

Makan J, Sharma S, Firoozi S, Whyte G, Jackson PG, McKenna WJ (2005) Physiological upper limits of ventricular cavity size in highly trained adolescent athletes. Heart 91(4):495-499

Malhotra A, Dhutia H, Finocchiaro G, Gati S, Beasley I, Clift P, Cowie C, Kenny A, Mayet J, Oxborough D, Patel K, Pieles G, Rakhit D, Ramsdale D, Shapiro L, Somauroo J, Stuart G, Varnava A, Walsh J, Yousef Z, Tome M, Papadakis M, Sharma S (2018) Outcomes of cardiac screening in adolescent soccer players. N Engl J Med 379(6):524-534

Marcus KA, Mavinkurve-Groothuis AM, Barends M, van Dijk A, Feuth T, de Korte C, Kapusta L (2011) Reference values for myocardial two-dimensional strain echocardiography in a healthy pediatric and young adult cohort. J Am Soc Echocardiogr 24(6):625-636

Maron BJ (1986) Structural features of the athlete heart as defined by echocardiography. J Am Coll Cardiol 7(1):190-203

Maron BJ, Roberts WC, McAllister HA, Rosing DR, Epstein SE (1980) Sudden death in young athletes. Circulation 62(2):218-229

Maron BJ, Epstein SE, Roberts WC (1986) Causes of sudden death in competitive athletes. J Am Coll Cardiol 7(1):204-214

May LJ, Punn R, Olson I, Kazmucha JA, Liu MY, Chin C (2013) Supine cycling in pediatric exercise testing: disparity in performance measures. Pediatr Cardiol.

McClean G, Riding NR, Ardern CL, Farooq A, Pieles GE, Watt V, Adamuz C, George KP, Oxborough D, Wilson MG (2017) Electrical and structural adaptations of the paediatric athlete's heart: a systematic review with meta-analysis. Br J Sports Med.

Morganroth J, Maron BJ, Henry WL, Epstein SE (1975) Comparative left ventricular dimensions in trained athletes. Ann Intern Med 82(4):521-524

Nishimura T, Yamada Y, Kawai C (1980) Echocardiographic evaluation of long-term effects of exercise on left ventricular hypertrophy and function in professional bicyclists. Circulation 61(4):832-840

Paridon SM, Alpert BS, Boas SR, Cabrera ME, Caldarera LL, Daniels SR, Kimball TR, Knilans TK, Nixon PA, Rhodes J, Yetman AT, C. o. A. H. American Heart Association Council on Cardiovascular Disease in the Young, and Y. Obesity (2006) Clinical stress testing in the pediatric age group: a statement from the American Heart Association Council on Cardiovascular Disease in the Young, Committee on Atherosclerosis, Hypertension, and Obesity in Youth. Circulation 113(15):1905-1920

Pela G, Crocamo A, Li Calzi M, Gianfreda M, Gioia MI, Visioli F, Pattoneri P, Corradi D, Goldoni M, Montanari A (2016) Sex-related differences in left ventricular structure in early adolescent nonprofessional athletes. Eur J Prev Cardiol 23(7):777-784

Picano E, Lattanzi F, Orlandini A, Marini C, L'Abbate A (1991) Stress echocardiography and the human factor: the importance of being expert. J Am Coll Cardiol 17(3):666-669

Pieles GE, Gowing L, Forsey J, Ramanujam P, Miller F, Stuart AG, Williams CA (2015) The relationship between biventricular myocardial performance and metabolic parameters during incremental exercise and recovery in healthy adolescents. Am J Physiol Heart Circ Physiol 309(12):H2067-2076

Rhodes J, Ubeda Tikkanen A, Jenkins KJ (2010) Exercise testing and training in children with congenital heart disease. Circulation 122(19):1957-1967
Roche SL, Vogel M, Pitkanen O, Grant B, Slorach C, Fackoury C, Stephens D, Smallhorn J, Benson LN, Kantor PF, Redington AN (2011) Isovolumic acceleration at rest and during exercise in children normal values for the left ventricle and first noninvasive demonstration of exercise-induced force-frequency relationships. J Am Coll Cardiol 57(9):1100-1107

Roche SL, Grosse-Wortmann L, Friedberg MK, Redington AN, Stephens D, Kantor PF (2014) Exercise echocardiography demonstrates biventricular systolic dysfunction and reveals decreased left ventricular contractile reserve in children after tetralogy of fallot repair. J Am Soc Echocardiogr.

Sakata K, Ino H, Fujino N, Nagata M, Uchiyama K, Hayashi K, Konno T, Inoue M, Kato H, Sakamoto Y, Tsubokawa T, Yamagishi M (2008) Exercise-induced systolic dysfunction in patients with nonobstructive hypertrophic cardiomyopathy and mutations in the cardiac troponin genes. Heart 94(10):1282-1287

Sanz-de la Garza M, Giraldeau G, Marin J, Grazioli G, Esteve M, Gabrielli L, Brambila C, Sanchis L, Bijnens B, Sitges M (2017) Influence of gender on right ventricle adaptation to endurance exercise: an ultrasound two-dimensional speckle-tracking stress study. Eur J Appl Physiol 117(3):389-396

Sharma S, Maron BJ, Whyte G, Firoozi S, Elliott PM, McKenna WJ (2002) Physiologic limits of left ventricular hypertrophy in elite junior athletes: relevance to differential diagnosis of athlete's heart and hypertrophic cardiomyopathy. J Am Coll Cardiol 40(8):1431-1436

Sheikh N, Papadakis M, Schnell F, Panoulas V, Malhotra A, Wilson M, Carre F, Sharma S (2015) Clinical profile of athletes with hypertrophic cardiomyopathy. Circ Cardiovasc Imaging 8(7):e003454

Stohr EJ, Gonzalez-Alonso J, Bezodis IN, Shave R (2014) Left ventricular energetics: new insight into the plasticity of regional contributions at rest and during exercise. Am J Physiol Heart Circ Physiol 306(2):H225-232

Utomi V, Oxborough D, Whyte GP, Somauroo J, Sharma S, Shave R, Atkinson G, George K (2013) Systematic review and metaanalysis of training mode, imaging modality and body size influences on the morphology and function of the male athlete's heart. Heart 99(23): 1727-1733

Voigt JU, Pedrizzetti G, Lysyansky P, Marwick TH, Houle H, Baumann R, Pedri S, Ito Y, Abe Y, Metz S, Song JH, Hamilton J, Sengupta PP, Kolias TJ, d'Hooge J, Aurigemma GP, Thomas JD, Badano LP (2015) Definitions for a common standard for 2D speckle tracking echocardiography: consensus document of the EACVI/ASE/ Industry Task Force to standardize deformation imaging. J Am Soc Echocardiogr 28(2):183-193

Warburton DE, Haykowsky MJ, Quinney HA, Blackmore D, Teo KK, Humen DP (2002) Myocardial response to incremental exercise in endurance-trained athletes: influence of heart rate, contractility and the Frank-Starling effect. Exp Physiol 87(5):613-622

Weidemann F, Jamal F, Kowalski M, Kukulski T, D’Hooge J, Bijnens B, Hatle L, De Scheerder I, Sutherland GR (2002a) Can strain rate and strain quantify changes in regional systolic function during dobutamine infusion, B-blockade, and atrial pacing-implications for quantitative stress echocardiography. J Am Soc Echocardiogr 15(5):416-424

Weidemann F, Jamal F, Sutherland GR, Claus P, Kowalski M, Hatle L, De Scheerder I, Bijnens B, Rademakers FE (2002b) Myocardial function defined by strain rate and strain during alterations in inotropic states and heart rate. Am J Physiol Heart Circ Physiol 283(2):H792-799

Publisher's Note Springer Nature remains neutral with regard to jurisdictional claims in published maps and institutional affiliations. 